This is an Accepted Manuscript of an article published by Taylor \& Francis Group in

Journal of Intellectual \& Developmental Disability on 15/11/2019, available online: https://doi.org/10.3109/13668250.2019.1680821

\title{
Clinicians' retrospective perceptions of failure to detect sexual abuse in a young man with autism and mild intellectual disability
}

\author{
Arvid Nikolai Kildahl ${ }^{1,2,3}$, Sissel Berge Helverschou ${ }^{2}$, Hanne Weie Oddli $^{3}$ \\ ${ }^{1}$ Regional Section Mental Health, Intellectual Disabilities/Autism, Oslo University \\ Hospital, Oslo, Norway \\ ${ }^{2}$ NevSom - Norwegian Centre of Expertise for Neurodevelopmental Disorders and \\ Hypersomnias, Oslo University Hospital, Oslo, Norway \\ ${ }^{3}$ Faculty of Social Sciences, University of Oslo, Oslo, Norway. \\ Arvid Nikolai Kildahl, Regional Section Mental Health, Intellectual \\ Disabilities/Autism, Oslo University Hospital, Dikemarksveien 39, 1385 Asker, \\ Norway.uxarvk@ous-hf.no+4790144601
}

Acknowledgements: We would like to thank Patricia Howlin for her helpful suggestions in the preparation of this manuscript and for vastly improving its language during the final revision. We would also like to thank Trine Lise Bakken for her helpful input during the first revision of the manuscript, and the anonymous referees for their highly constructive input.

Author note: This research was funded by the Oslo University Hospital through the authors' work as clinicians. The funding body did not impose any restrictions on free access to or publication of the research data. There are no conflicts of interests to disclose. All authors have contributed to, seen, and approved of the manuscript, and agree to the order of authors as listed on the title page. 


\title{
Clinicians' retrospective perceptions of failure to detect sexual abuse in a young man with autism and mild intellectual disability
}

\author{
Background: Individuals with intellectual disability (ID) and autism spectrum \\ disorder (ASD) are at increased risk of sexual abuse. However, little is known \\ about facilitating detection and disclosure. One year after discharge from a \\ specialized psychiatric ward, a young man with mild ID and ASD disclosed \\ previously unknown sexual abuse. The aim of the present study was to explore \\ clinicians' perceptions of their failure to detect abuse. \\ Method: Interpretative phenomenological analysis was used to explore five staff \\ members' perceptions, with data being collected through an individual, semi- \\ structured interview. \\ Results: Staff reported behaviours that, in retrospect, they understood as possible \\ indicators of abuse and/or attempts by the patient to disclose. Factors contributing \\ to non-detection included insufficient trauma sensitivity, lack of exploration, and \\ diagnostic overshadowing. \\ Conclusions: Symptoms of PTSD should be routinely explored in individuals \\ with ASD and ID referred for psychiatric assessment - even in the absence of \\ known trauma or abuse.
}

Keywords: autism spectrum disorder; intellectual disability; sexual abuse; trauma; post-traumatic stress disorder; PTSD

Individuals with intellectual disability (ID) are at increased risk of sexual abuse (Byrne, 2018). Individuals with mild ID and individuals with co-occurring autism spectrum disorder (ASD) seem to be particularly at risk (Gil-Llario, Morell-Mengual, DíazRodríguez \& Ballester-Arnal, 2019; Dinkler et al., 2017; Soylu, Alpaslan, Ayaz, Esenyel \& Oruc, 2013). The social and communication difficulties of individuals with ASD and ID also exacerbate problems in detecting and confirming suspected abuse in this group (McDonnell et al., 2019). 
Many individuals with ASD and ID have limited verbal skills, but even those with good verbal proficiency frequently have difficulties reporting their experiences (Helverschou, Bakken \& Martinsen, 2011). While findings from the general population suggest that sexual abuse often remains undisclosed years after its occurrence (Alaggia, Collin-Vézina, \& Lateef, 2017), individuals with ID seem to be even less likely to disclose abuse (Soylu et al., 2013). For individuals with ASD and ID it may be years before abuse is reported (Carrigan \& Allez, 2017), and sometimes it is only discovered by chance (Rowsell, Clare \& Murphy, 2013). Knowledge regarding facilitation of detection and disclosure of abuse is currently sparse.

Post-traumatic stress disorder (PTSD) and other trauma reactions are common sequelae to sexual abuse both in the general population and people with ID (Soylu et al., 2013). However, symptoms of PTSD can be much more challenging to identify in this latter group (Daveney, Hassiotis, Katona, Matcham \& Sen, 2019; Byrne, 2018) and particularly in those with co-occurring ASD (Kildahl, Bakken, Iversen \& Helverschou, 2019). It has been suggested that trauma reactions in individuals with ASD and ID may easily be misinterpreted and attributed, instead, to the underlying condition or to cooccurring disorders such as anxiety or depression (Mevissen, Didden \& de Jongh, 2016; Kildahl et al., 2019). This has been referred to as diagnostic overshadowing (Helverschou et al., 2011; Mason \& Scior, 2004; Reiss, Levitan \& Szyszko, 1982).

Many clinicians, families and professional caregivers are unaware of how to detect possible symptoms of abuse or trauma in people with ASD and ID and it has been suggested (Kerns, Newschaffer \& Berkowitz, 2015) that multi-disciplinary approaches are needed to improve recognition of PTSD in this group. This includes the use of qualitative research methodologies (Kerns et al., 2015) and interpretative phenomenological analysis (IPA; Smith, 2011; Smith, Flowers \& Larkin, 2009) has 
been suggested as an effective means of exploring how individuals understand and make sense of their lived experience (Smith, 2017). IPA represents what may be considered a double hermeneutic in that "the researcher is trying to make sense of the participant trying to make sense of their personal and social world" (Smith, 2004, p. 40).

Although IPA is considered applicable across a wide range of areas (Smith, 2017), in health research it has primarily been used to explore patients' perspectives (Smith, 2011), including the experience of trauma by adults with ID (Mitchell, Clegg \& Furniss, 2006). However, Malterud (2001) suggests that experienced clinicians accumulate knowledge and understanding not only through the research literature, but also through their practical experience. Exploration of how clinicians make sense of their experiences may therefore be a helpful approach to investigate clinical phenomena where current knowledge is sparse.

No previous study has explored clinicians' retrospective perceptions of failure to detect sexual abuse in ASD and ID and the current investigation was undertaken following the disclosure of sexual abuse by a young man with ASD and mild ID. He told his primary carer that for years he had been coerced into a variety of sexual acts by a male peer who also had ID. These reports were later substantiated by a police investigation. One year prior to the disclosure he had been committed to a specialized psychiatric inpatient ward for individuals with ASD/ID because of suspected psychosis and depression, and increased aggression.

At referral, the patient was in his late twenties. He had been diagnosed with ASD at the age of four and with mild ID in his early teens. He had relatively good verbal proficiency, scoring just below the threshold for ID on standardized measures of verbal ability. His parents were divorced but he had a close relationship with both of 
them, living mainly with his mother and two younger siblings until he moved into a supported care environment at the age of 20 . He was described as having severe difficulties in social communication from an early age, as well as readily showing frustration or anger. He was also intensely preoccupied with several special interests. Diagnostic formulation concluded that he had subthreshold symptoms of depressive disorder. Prior to referral these had been more severe and likely met criteria for a major depressive episode. He no longer met criteria for a previously diagnosed obsessivecompulsive disorder; diagnoses of ASD and mild ID were confirmed. During the 5 months he spent as an inpatient, there was no suspicion of sexual abuse despite detailed assessments, interviews with carers and family and a thorough medical history.

Diagnostic formulation and treatment plan during and following his stay were thus not fully informed.

The study aims to address the following research questions:

(1) What do mental health professionals retrospectively perceive as contributing to the failure to detect sexual abuse?

(2) With the current knowledge of sexual abuse, are there behaviours or symptoms that they interpret differently?

\section{Method}

IPA was chosen due to the combination of its phenomenological, idiographic and hermeneutic components to investigate how staff made sense of their failure to detect sexual abuse (Smith, 2011; Smith et al., 2009), including exploration of whether staffs' interpretations of the patient's symptoms and behaviours had changed in light of the new information. 


\section{Participants}

Five team members from the ward were recruited for a face-to-face, in-depth, individual, semi-structured interview. To elicit as wide a range of perspectives as possible, staff members with varying professional backgrounds, varying roles in the assessment, and varying relationships with the patient were recruited (see Table 1). All informants had several years of experience in specialist mental health services for people with ASD/ID, and had also worked with cases involving sexual abuse. Although they had all completed a trauma sensitivity program, this was a general program that had no specific focus on trauma in ASD/ID.

[Table 1 about here]

\section{Materials}

The interview schedule (see appendix) was developed by the first author in collaboration with the other authors following recommendations by Smith et al. (2009). Its development was informed by recent research on sexual abuse, trauma and PTSD in individuals with ASD and/or ID (Kildahl et al., 2019; Rumball, 2018; Carrigan \& Allez, 2017; Soylu et al., 2013).

\section{Procedure}

The study was approved by the hospital's Data Protection Official for Research and the head of the ward. Written, informed consent was obtained from the patient's legal guardian and from the informants.

Interviews were conducted by the first author, audio recorded and transcribed verbatim. Informants were informed of topics prior to interviews, and the semistructured schedule was used to discuss informants' experience of the patient's 
admission, given their current knowledge about his sexual abuse. Interview duration ranged from 20 to 54 minutes.

\section{Data Analysis}

Analyses of interviews were carried out in accordance with the principles outlined by Smith et al. (2009). The first author took the lead in analysis, discussing and developing emergent themes in collaboration with the second and third author. Authors two and three each read full transcripts of at least two interviews.

Transcripts were read and re-read, with initial descriptive notation in the righthand margin. In line with recommendations by Smith et al. (2009), this process was repeated several times with different foci before emergent themes were developed and noted in the left-hand margin. Themes were transferred to word processing software and analyses were undertaken to identify clusters and find connections between themes. A master table of themes was created including extracts for each theme. All interviews were analysed separately prior to searching for themes across interviews. Finally, a master table of themes and extracts for all informants was created. Themes were discussed with informants and other clinical specialists, as well as with other staff from the ward. The patient's mother and one informant read and provided feedback on an early draft of this manuscript.

The first author is a clinical psychologist and a colleague of the informants, but does not work in the ward in question. Author two is a clinical psychologist and researcher specializing in mental health issues in ASD, who has previously collaborated with the department for research purposes. Author three is a clinical psychologist and psychotherapy researcher with extensive experience in qualitative research, but with little prior experience of conducting research on mental health issues in ASD and ID. 
She had no prior knowledge of, or affiliation with, the department where the ward is located.

\section{Results}

In the presentation below, themes are identified as subheadings, while subthemes are identified in italics (see also table 2). Recommendations from Smith (2011) have been followed, including extracts from at least three different informants for each theme and all informants being represented by at least one extract. In the extracts below informants are identified by a number; to preserve anonymity, these numbers do not correspond to the order of participants in Table 1. Data extracts have been translated from Norwegian and edited for clarity.

[Table 2 about here]

\section{We did not consider trauma and abuse, and we did not ask him}

There was a persistent failure to consider trauma and abuse throughout the assessment, which informants considered significant in their failure to detect abuse. Lack of hypotheses about the possibility of trauma and abuse seemed to occur primarily due to the patient not displaying characteristics viewed by informants as typical indicators of trauma. The informants expressed insecurity in their own ability to separate ASD symptoms from signs of abuse. Lack of knowledge about behavioural signs of PTSD in ASD may have contributed to the failure both to detect abuse and/or to consider it in the first place. The patient's interpersonal sensitivity was also a factor in informants' avoidance of uncomfortable topics in conversation with him. Their primary focus seemed to be on reducing the patient's discomfort and agitation, possibly at the expense of exploration of previous experiences, trauma and abuse. 
"We should have thought of trauma. I don't think we even considered it, because we thought that he had a fantastic mother and father and it had been very safe for him. We just assumed there wasn't any" [4]. The patient had grown up in a stable and affluent family, and this was seen by informants as contributing to why they did not think of trauma or abuse. The patient did not have characteristics that the informants associated with trauma, and there was no readily available information about previous trauma. Informants thus failed to consider trauma as a possible explanation for the patient's difficulties. "Maybe I'm not very good at seeing such things, but it did not cross my mind at all" [2]. This omission of trauma and abuse as hypotheses thus did not seem to be a conscious decision by informants, indicating that they were not routinely assessing trauma and PTSD symptoms.

Informants reported insecurity in their own ability to conduct assessment of trauma or abuse in ASD and ID, reflecting on a lack of available assessment tools, procedures and strategies:

Is there something we could have seen while he was here? What should we have been looking for? What would have been autism symptoms and what would have been symptoms of trauma? So no, it sort of stopped for me, because there's an overlap and it's hard to identify which is which" [1].

Diagnostic interviews had been conducted with the patient, but this had been challenging because of his broader communication difficulties: "It was often challenging, as he had a distinctive way of speaking. It wasn't always easy to get answers to the questions you asked "[4]. At the time of the assessment, the abuse was not known to the patient's family or his professional caregivers. Thus, the only person who could have disclosed the abuse was the patient himself: "I think it would have needed to be direct questions. Within a safe context, as a standardized question, without 
him feeling singled out, then maybe. It would have been difficult to have a conversation about it" [3]. However, despite having an adequate expressive vocabulary to answer such questions, the patient was not asked directly about trauma and abuse. Informants seemed to be unsure how to ask and what to look for, not knowing whether there were any particular behaviours or symptoms that should have elicited suspicion of abuse.

Moreover, the patient was perceived to be interpersonally sensitive. He often misunderstood seemingly innocent or harmless utterances. When this occurred he became agitated and withdrew from the situation. "After a while I was sort of just present. I could have talked, but I did not, at least as little as possible, because the situation could change so suddenly if I did" [3]. Informants perceived these unpredictable reactions as characteristic throughout the admission, and as having influenced the assessment as they led to staff making fewer conversational initiatives. "I don't really know how we could have asked about abuse without him feeling criticized" [4]. Interpersonal sensitivity was thus seen by informants as limiting the topics the patient was asked about.

\section{He tried to tell us - indirectly}

Informants saw their inability to interpret the patient's indirect communications as contributing to the failure to detect abuse. Rather than the patient's lack of disclosure, they seemed to focus on their own failure to explore and understand these communications. While staff had been aware of the patient's indirect style of communication at the time, information about the abuse led to a re-appraisal and reinterpretation of such communications. Informants' tendency to attribute any mention of sexually related topics to ASD-related special interests was seen as particularly significant in their failure to explore what was later understood as attempted disclosure. 
Informants reported the patient making what they subsequently understood to be initiatives involving indirect communications of distress. These included leaving pictures or text related to death or suicide for staff to find, without verbally engaging in conversation about these. He would for instance find pictures of tombstones on the internet and leave the browser open before asking for help with his computer.

It was his way of letting us know. You sort of had to guess. After a while, when we got to know him, it got easier. In the beginning, it was very challenging to understand what he wanted to communicate. And looking back, I don't think we really understood it, either [4].

This indirectness involved informants having to interpret and guess what the patient intended to communicate. However, even if they understood them as explicit communicative acts, they did not think that they had fully grasped their meaning at the time.

Two informants suspected that the patient had made indirect attempts to disclose the abuse: "I have this feeling that he wanted to convey it, in a way, in his own peculiar way, but that he didn't know how - that he would have needed help to do it" [4]. What informants perceived as specific attempts of disclosure involved unusual sexual topics, and curiosity about staff reactions. One informant recalled the patient contemplating buying a somewhat unusual sex toy:

He had some sexual preoccupations which we explained by his autism. Some of it might have been, but I think it is more about the abuse. He talked about buying a big horse dildo. He wondered whether he could have it sent to the ward, and whether people would see that he had ordered it [4].

At the time, this behaviour was attributed to ASD-related special interests, and such interpretations likely contributed to lack of exploration. 
He was very into looking at videos on the internet, watching videos of animals of the same sex having intercourse. He talked about hermaphroditic animals, and he had questions about that and whether animals could be with other animals of the same sex. And I've thought about that later, because I've wondered... Back then, I thought about it as a curiosity or as a special interest, because there was no sign that he felt stressed or negatively affected by what we were talking about [3].

After learning of the sexual abuse, informants interpreted these topics differently. The fact that the patient discussed these issues in a neutral tone, displaying no apparent signs of distress or tension, seemed to have contributed to staffs' attribution of the symptoms to ASD and their lack of further exploration.

Throughout the admission, the patient expressed a reluctance to return home. This was attributed to the better support he received in hospital. "I remember him saying 'If I have to go back there it won't get any better, and then it doesn't matter what you do here'. When I think of that, it's just like 'shit, now I finally understand'” [4]. Informants understood this differently in retrospect, as they were now aware that the abuse had been re-initiated following discharge, expressing that they had probably misinterpreted this reluctance at the time. "I understood that he wasn't looking forward to going back. And maybe we should have done more about that, maybe we should have asked why?" [5]. Informants' re-appraisal of these behaviours and utterances in light of information about the abuse indicates that they could have been explored further, and possibly interpreted differently at the time.

\section{Possible signs of abuse were attributed to ASD or depression}

"He had quite a few symptoms. We understood them differently, but they probably were associated with trauma. We were too quick to find an explanation. I think we explained too much by his autism" [4]. Informants reported observing behaviours that they in retrospect suspected might have been signs of abuse or trauma, which they at the time 
had attributed to the patient's ASD. This suggests that diagnostic overshadowing played an important part in the failure to detect sexual abuse. Informants were aware of challenges associated with diagnostic overshadowing, but the re-appraisals of symptoms indicate that such awareness was not sufficient to overcome these in the current case.

All informants saw the patient as irritable: "I remember he would withdraw and be irritated for a while. If he was annoyed with a particular staff member, it would take days until he would talk to them again" [2]. This irritability was perceived by informants as particularly unpredictable and disproportional, frequently leading to angry outbursts. These were described as having occurred since childhood, but had intensified and increased in frequency prior to the admission. "He got angry very quickly, and angrier. With other patients it's often somehow understandable. But with him it was kind of 'Did that make you react? - I would have never imagined"' [4]. Outbursts were described as particularly unpredictable when compared to other patients with ASD, ID and mental health issues. Irritability and outbursts were attributed to ASD and frequent misunderstandings in social interaction, but informants retrospectively doubted whether this was accurate: "Maybe his aggression, maybe it was caused by the abuse. Maybe his outbursts wouldn't have been that intense if he didn't have those experiences?" [1].

Even though he frequently sought social contact, the patient rarely seemed at ease in social settings and was viewed by informants as guarded and anxious. "He often talked a lot, but when he was talking, he paid very close attention to us, to what we said and did. He always had a sort of guarded readiness about him during any kind of social interaction" [5]. When speaking, often about his special interests, he was perceived as continually scanning others for their reactions. This anxiety had been challenging to categorise and was understood as secondary to his ASD: 
He was worried about quite a few things and he seemed generally alert and guarded a lot of the time. At the time, we understood it as a sort of general anxiety which was secondary to his autism and difficulties understanding things. We explained a lot by those difficulties, when I think about it now [4].

The unfocussed nature of the patient's anxiety was thus seen as an indication that it might have been associated with the abuse.

The patient was afraid of doing something wrong, and if he got the impression anyone thought he had, he would react with distress or anger:

He was afraid of making mistakes. He sort of couldn't receive feedback on his behaviour - that he had done something he shouldn't have - while still maintaining that he was good enough as a person [5].

This was retrospectively understood by informants as difficulties in coping with feelings of guilt and shame, but at the time was ascribed to ASD: "I thought it was because he had such severe autism that he didn't understand whether he had done anything wrong. I think it may have been related to abuse, that he had understood that something wasn't right" [4]. Attributing these behaviours to difficulties understanding social communication, without sufficient exploration, was seen as likely to have contributed to diagnostic overshadowing.

Finally, the patient's mood was perceived as flat, with few expressions of joy. "I've thought about afterwards how he was very rarely happy" [5]. At the time, this was attributed to a previous depressive disorder. The exception was when he talked about or did something relating to his special interests, during which he would show increased energy and some positive emotion. In retrospect, his failure to show positive emotions was seen as possibly associated with the abuse. 


\section{Discussion}

Diagnostic overshadowing, failure to consider trauma and abuse as viable hypotheses, and lack of sufficient exploration of possible attempts at disclosure, were reported by informants as contributing to the failure to detect sexual abuse in the current case. Interactions between these putative mechanisms may also have influenced their clinical practice. For example, had informants considered trauma and abuse in the first place, it is possible that they would have made more strenuous attempts to overcome challenges to the assessment, such as lack of assessment tools or the patient's interpersonal sensitivity. The current findings underline the need for further knowledge about the identification of PTSD in individuals with ASD and ID. It is also evident that professionals conducting psychiatric assessments in this population need to become sufficiently trauma sensitive. Findings further suggest that trauma and abuse should be routinely investigated in psychiatric assessment in ASD and ID, including assessment of PTSD symptoms in the absence of known trauma.

There is also a need for identification of behavioural equivalents to PTSD symptoms in individuals with ASD and ID. Experience from the current study indicates that irritability, angry outbursts, guardedness and anxiety, reduced expressions of joy, as well as issues of guilt and shame, may be candidates for such equivalents. While these behaviours correspond to previously reported symptoms of PTSD in this population (Kildahl et al., 2019), they are unlikely to be specific to PTSD (Helverschou et al., 2011). Furthermore, expression of symptoms following sexual abuse, including PTSD symptoms, is likely to be influenced not only by ASD and ID but also by cognitive, social, and emotional development (Mason-Roberts et al., 2018; McCarthy et al., 2017; Cloitre et al., 2009), the characteristics of the abuse itself (Ehlers \& Clark, 2000), and other factors affecting coping and management (Ehlers \& Clark, 2000). 
As is well documented, ASD and ID are highly heterogeneous conditions (Lai, Lombardo \& Baron-Cohen, 2014; Bertelli, Salvador-Carulla \& Harris, 2016). Thus, it is doubtful whether there is a unique set of behavioural equivalents that will be applicable to all individuals with ASD and ID who have experienced trauma or abuse. Even with improved knowledge about behavioural equivalents, an individualised approach to psychiatric assessment in this population is likely to be necessary. This includes the collection of historical information on the development and presentation of ASD and ID, as well as on cognitive, emotional and social development. Such information is necessary to identify changes that may indicate the presence of any psychiatric disorder, including PTSD (Kildahl et al., 2019; Mevissen et al., 2016; Helverschou et al., 2011). While all the informants had undergone a trauma sensitivity training program, the program did not focus on potential expressions of trauma and abuse in ASD and ID. This may have contributed to the failure to consider abuse and trauma in the current case, suggesting that ASD/ID-specific training is necessary.

While the identification of behavioural equivalents is important, it is also unlikely to be sufficient to reliably identify signs of trauma and abuse in clinical assessments. In the current case, it is unclear whether behavioural equivalents to PTSD symptoms would have been recognized even if the staff had the necessary knowledge, as they failed to consider abuse and trauma in the first place. Trauma-informed care is a systems-focused framework focusing on the impact of trauma as an influencing factor in any person's current presentation and perspective (Truesdale et al., 2019; Keesler, 2014). To detect a history of sexual abuse, it is necessary for staff to be fully aware of signs and symptoms indicative of abuse and for the environment to be sufficiently trauma-informed to detect these. The current findings suggest that trauma-informed care in ASD needs to include exploration and attempts to understand what may appear to be 
special interests. Indirect communication strategies are not uncommon in ASD (Jones et al., 2018), and what may appear to be special interests may involve attempts to communicate something distressing through a non-threatening topic.

Diagnostic overshadowing, that is the process of wrongly ascribing symptoms of a psychiatric disorder to ASD, ID or other conditions, has been described as an important issue in psychiatric assessment in ASD/ID (Helverschou et al., 2011; Mason \& Scior, 2004; Reiss et al., 1982). Knowledge regarding identification of PTSD in individuals with ASD and ID seems particularly limited (Kildahl et al., 2019; Rumball, 2019; Mevissen et al., 2016), and the symptoms that seem to be most easily observable in this population are not specific to PTSD (Kildahl et al., 2019). In line with the results from the current study, this indicates the need for a heightened awareness of the possible role of diagnostic overshadowing when it comes to PTSD, trauma and abuse in individuals with ASD and ID. The current findings further suggest that diagnostic overshadowing may be an issue even in specialized environments where clinicians are aware of the phenomenon and have specific experience conducting psychiatric assessments in individuals with ASD and ID. This indicates that overcoming diagnostic overshadowing is a continuous, ongoing process, requiring clinicians constantly to reflect critically on their own diagnostic practice.

Psychiatric assessment tools frequently explore symptoms of PTSD by initially probing for the presence of traumatic incidents (e.g. Sheehan et al., 1998). If no incident is known or reported, symptoms of PTSD are not further investigated. This may lead to information crucial for the differential diagnostic assessment being overlooked, and to signs of abuse or symptoms of PTSD being missed or misattributed (Mevissen et al., 2016). The increased risk of abuse in people with ASD and ID, together with the fact that abuse may be unknown to others, suggests that possible symptoms of PTSD should 
be routinely assessed during psychiatric assessments in this population, even in the absence of known trauma.

\section{Limitations}

The current study was based on clinicians' perceptions in a single case and may therefore have limited generalizability. The use of IPA allowed for in-depth exploration of clinicians' experiences, including their re-appraisals of the patient and his symptoms after learning of the sexual abuse. Use of IPA also allowed for exploration of what may have contributed to the failure to detect sexual abuse in the first place. Further research is necessary to investigate whether these are common mechanisms in the non-discovery of sexual abuse in this population.

The first author's collegial relationship with the informants may have affected interviews, analyses and interpretations by making these less critical of the informants' work. However, it was through this relationship that the first author learned about this case, and in the absence of such a relationship it is unlikely that the current study would have been conducted. It is also possible that the interviewer's familiarity with the informants may have encouraged them to reflect more critically on their own practice than they would have done with an unfamiliar interviewer. The authors sought to counter any bias arising from these personal relationships by authors two and three remaining unaware of the identity of the informants or the patient. Author three had no prior knowledge of the ward or its staff.

In IPA research, the researchers' pre-understanding is assumed to have an effect on the research process, including analyses and interpretations (Smith et al., 2009). The first author's background as a clinical psychologist working in mental health in ASD/ID is likely to have affected development of themes, interpretations, and the language used to describe them. Emerging themes were therefore discussed with the second and third 
author throughout the analytic process, where the third author provided an important corrective. The authors further sought to counter these biases by rigorously adhering to the principles of the analytic process and providing extracts to substantiate interpretations.

As the interviews were retrospective, they may have been influenced by recall bias on the informants' part. However, the interview schedule invited informants to reflect also on their re-appraisals and on their thoughts when they learned of the abuse in an attempt to counter such bias. The time that had elapsed since the patient's admission, however, may still have affected their recall and there may have been other symptoms that they had not noticed or no longer remembered.

\section{Conclusions}

Further research is needed to identify mechanisms for facilitating detection of sexual abuse in individuals with ASD and ID, as well as on which signs and symptoms should trigger suspicion of such abuse. The current findings suggest that a more systematic approach to assessment may increase the likelihood that sexual abuse is detected. This includes routinely assessing symptoms of PTSD, as well as always considering trauma and abuse as viable hypotheses. The current study also underlines the importance of assessments taking place in a trauma informed environment, as well as exploring unusual, sexually related utterances by individuals with ASD and ID, and continually working to overcome diagnostic overshadowing. Finally, the use of IPA to explore the experience of clinicians provided valuable insights that may have been challenging to obtain through the use of less explorative methodologies. 


\section{References}

Alaggia, R., Collin-Vézina, D., \& Lateef, R. (2017). Facilitators and Barriers to Child Sexual Abuse (CSA) Disclosures: A Research Update (2000-2016). Trauma, Violence, \& Abuse, 1524838017697312. doi:10.1177/1524838017697312

Bertelli, M. O., Salvador-Carulla, L., \& Harris, J. (2016). Chapter 2. Classification and diagnosis. In C. Hemmings \& N. Bouras (Eds.). Psychiatric and Behavioural Disorders in Intellectual and Developmental Disabilities. Cambridge, UK: Cambridge University Press.

Byrne, G. (2018). Prevalence and psychological sequelae of sexual abuse among individuals with an intellectual disability: A review of the recent literature. Journal of Intellectual Disabilities, 22(3), 294-310.

Carrigan, N., \& Allez, K. (2017). Cognitive behaviour therapy for post-traumatic stress disorder in a person with an autism spectrum condition and intellectual disability: A case study. Journal of Applied Research in Intellectual Disabilities, 30(2), 326-335.

Cloitre, M., Stolbach, B. C., Herman, J. L. van der Kolk, B., Pynoos, R. Wang, J., \& Petkova, E. (2009). A developmental approach to complex PTSD: Childhood and adult cumulative trauma as predictors of symptom complexity. Journal of Traumatic Stress, 22(5), 399-408.

Daveney, J., Hassiotis, A., Katona, C., Matcham, F., \& Sen, P. (2019). Ascertainment and prevalence of post-traumatic stress disorder (PTSD) in people with intellectual disabilities. Journal of Mental Health Research in Intellectual Disabilities, DOI: 10.1080/19315864.2019.1637979

Dinkler, L., Lundström, S., Gajwani, R., Lichtenstein, P., Gillberg, C., \& Minnis, H. (2017). Maltreatment-associated neurodevelopmental disorders: a co-twin control analysis. The Journal of Child Psychology and Psychiatry, 58(6), 691701.

Ehlers, A., \& Clark, D. M. (2000). A cognitive model of posttraumatic stress disorder. Behaviour Research and Therapy, 38(4), 319-345.

Gil-Llario, M. D., Morell-Mengual, V., Díaz-Rodríguez, I., \& Ballester-Arnal, R. (2019). Prevalence and sequelae of self-reported and other-reported sexual abuse in adults with intellectual disability. Journal of Intellectual Disability Research, 63(2), 138- 148. 
Helverschou, S. B., Bakken, T. L., \& Martinsen, H. (2011). Psychiatric disorders in people with autism spectrum disorders: Phenomenology and recognition. In J.L. Matson, P. Strurmey (Eds.), International Handbook of Autism and Pervasive Developmental Disorders (pp.53-74), New York: Springer.

Jones, C. R. G., Simonoff, E., Baird, G., Pickles, A., Marsden, A. J. S., Tregay, J., . . Charman, T. (2018). The association between theory of mind, executive function, and the symptoms of autism spectrum disorder. Autism Research, 11(1), 95-109.

Keesler, J. M. (2014). A call for the integration of trauma-informed care among intellectual and developmental disability organizations. Journal of Policy and Practice in Intellectual Disabilities, 11(1), 34-42.

Kerns, C. M., Newschaffer, C. J., \& Berkowitz, S. J. (2015). Traumatic childhood events and autism spectrum disorder. Journal of Autism and Developmental Disorders, 45(11), 3475-3486.

Kildahl, A. N., Bakken, T. L., Iversen, T. E., \& Helverschou, S. B. (2019). Identification of post-traumatic stress disorder in individuals with autism spectrum disorder and intellectual disability: A systematic review. Journal of Mental Health Research in Intellectual Disabilities, 12(1-2), 1-25.

Lai, M. C., Lombardo, M. V. \& Baron-Cohen, S. (2014). Autism. Lancet, 383(8), 896910.

Malterud, K. (2001). The art and science of clinical knowledge: evidence beyond measures and numbers. Lancet, 358(9279), 397-400.

Mason, J., \& Scior, K. (2004). 'Diagnostic overshadowing' amongst clinicians working with people with intellectual disabilities in the UK. Journal of Applied Research in Intellectual Disabilities, 17(2), 85-90. DOI:10.1111/j.13602322.2004.00184.x

Mason-Roberts, S., Bradley, A., Karatzias, T., Brown, M., Paterson, D., Walley, R., ... Sirisena, C. (2018). Brief report: Multiple traumatisation and subsequent psychopathology in people with intellectual disabilities and DSM-5 PTSD: a preliminary study. Journal of Intellectual Disability Research, 62(8), 730-736.

McCarthy, J., Blanco, R. A., Gaus, V. L., Razza, N. J., \& Tomasulo, D. J. (2017). Trauma-and stressor-related disorders. In R. J. Fletcher, J. Barnhill \& S.-A. Cooper (Eds.) DM-ID 2. Diagnostic Manual-Intellectual Disability: A 
Textbook of Diagnosis of Mental Disorders in Persons with Intellectual

Disability. Kingston, New York: NADD - National Association for the Dually Diagnosed.

McDonnell, C. G., Boan, A. D., Bradley, C. C., Seay, K. D., Charles, J. M., \& Carpenter, L. A. (2019). Child maltreatment in autism spectrum disorder and intellectual disability: results from a population-based sample. The Journal of Child Psychology and Psychiatry, 60(5), 576-584.

Mevissen, L., Didden, R., \& de Jongh, A. (2016). Assessment and treatment of PTSD in people with intellectual disability. In Martin, C., Preedy, V. \& Patel, V. B. (Eds.) Comprehensive Guide to Post-Traumatic Stress Disorder. New York: Springer.

Mitchell, A., Clegg, J., \& Furniss, F. (2006). Exploring the meaning of trauma with adults with intellectual disabilities. Journal of Applied Research in Intellectual Disabilities, 19(2), 131-142.

Reiss, S., Levitan, G. W., \& Szyszko, J. (1982). Emotional disturbance and mental retardation: Diagnostic overshadowing. American Journal of Mental Deficiency, $86(6), 567-574$.

Rowsell, A. C., Clare, I. C. H., \& Murphy, G. H. (2013). The psychological impact of abuse on men and women with severe intellectual disabilities. Journal of Applied Research in Intellectual Disabilities, 26(4), 257-270.

Rumball, F. (2019). A systematic review of the assessment and treatment of posttraumatic stress disorder in individuals with autism spectrum disorder. Review Journal of Autism and Developmental Disorders, 6(3), 294-324. DOI:10.1007/s40489-018-0133-9

Sheehan, D. V., Lecrubier, Y., Sheehan, K. H., Amorim, P., Janavs, J., Weiller, E., . . Dunbar, G. C. (1998). The Mini-International Neuropsychiatric Interview (M.I.N.I): The development and validation of a structured diagnostic psychiatric interview for DSM-IV and ICD-10. The Journal of Clinical Psychiatry, 59(Suppl 20), 22-33.

Smith, J. A. (2004). Reflecting on the development of interpretative phenomenological analysis and its contribution to qualitative research in psychology. Qualitative Research in Psychology, 1(1), 39-54. DOI: 10.1191/1478088704qp004oa 
Smith, J. A. (2011). Evaluating the contribution of interpretative phenomenological analysis. Health Psychology Review, 5(1), 9-27. DOI:10.1080/17437199.2010.510659

Smith, J. A. (2017). Interpretative phenomenological analysis: Getting at lived experience. The Journal of Positive Psychology, 12(3), 303-304.

Smith, J. A., Flowers, P., \& Larkin, M. (2009). Interpretative Phenomenological Analysis. Theory, Method and Research. London, UK: Sage publications.

Soylu, N., Alpaslan, A. H., Ayaz, M., Esenyel, S., \& Oruc, M. (2013). Psychiatric disorders and characteristics of abuse in sexually abused children and adolescents with and without intellectual disabilities. Research in Developmental Disabilities, 34(12), 4334-4342.

Truesdale, M., Brown, M., Taggart, L., Bradley, A., Paterson, D., Sirisena, C., ... Karatzias, T. (2019). Trauma-informed care: A qualitative study exploring the views and experiences of professionals in specialist health services for adults with intellectual disabilities. Journal of Applied Research in Intellectual Disabilities, DOI:10.1111/jar.12634 
Table 1 Informants

\begin{tabular}{|c|c|c|c|c|}
\hline Profession & Gender & Age & $\begin{array}{l}\text { Role in the } \\
\text { assessment }\end{array}$ & $\begin{array}{l}\text { Relationship with the } \\
\text { patient }\end{array}$ \\
\hline $\begin{array}{l}\text { Clinical } \\
\text { Psychologist }\end{array}$ & $\mathrm{F}$ & $\begin{array}{l}\text { Late } \\
\text { twenties }\end{array}$ & $\begin{array}{l}\text { Responsible for } \\
\text { carrying out the } \\
\text { assessment } \\
\text { Patient's individual } \\
\text { therapist } \\
\text { Team member }\end{array}$ & $\begin{array}{l}\text { Close. Patient would } \\
\text { spontaneously seek her } \\
\text { out to ask for } \\
\text { conversations whenever } \\
\text { something had happened } \\
\text { that he was not pleased } \\
\text { or felt bad about. Office } \\
\text { inside the ward, which } \\
\text { facilitated frequent } \\
\text { informal contact with the } \\
\text { patient. }\end{array}$ \\
\hline Psychiatrist & $\mathrm{F}$ & Early sixties & $\begin{array}{l}\text { Responsible for } \\
\text { medical aspects of } \\
\text { the admission } \\
\text { Team member }\end{array}$ & $\begin{array}{l}\text { More peripheral. Office } \\
\text { in the ward corridor, } \\
\text { frequent informal contact } \\
\text { with the patient. }\end{array}$ \\
\hline $\begin{array}{l}\text { Learning } \\
\text { disability } \\
\text { nurse }\end{array}$ & $\mathrm{F}$ & $\begin{array}{l}\text { Early } \\
\text { thirties }\end{array}$ & $\begin{array}{l}\text { Team leader } \\
\text { Milieu therapist }\end{array}$ & $\begin{array}{l}\text { Close. Visited the patient } \\
\text { prior to admission, and } \\
\text { was the patient's contact } \\
\text { nurse most of her shifts. }\end{array}$ \\
\hline $\begin{array}{l}\text { Learning } \\
\text { disability } \\
\text { nurse }\end{array}$ & $\mathrm{M}$ & Late thirties & $\begin{array}{l}\text { Milieu therapist } \\
\text { Team member }\end{array}$ & $\begin{array}{l}\text { Close. Was the patient's } \\
\text { contact nurse many of his } \\
\text { shifts. }\end{array}$ \\
\hline $\begin{array}{l}\text { Psychiatric } \\
\text { nurse }\end{array}$ & M & Late forties & Milieu therapist & $\begin{array}{l}\text { More peripheral. Spent } \\
\text { some shifts with the } \\
\text { patient, often the second } \\
\text { staff member to } \\
\text { accompany the patient on } \\
\text { outings. }\end{array}$ \\
\hline
\end{tabular}

Table 1. Overview of the informants' professional background, gender, age, and roles in the assessment. Appraisals of their relationship with the patient was done by the first author based on interview data, and have been validated with all informants. 
Table 2 Themes and subthemes

\begin{tabular}{ll}
\hline Themes & Subthemes \\
\hline We did not consider trauma and abuse, and we did not ask him (5) & Did not think of trauma or abuse (4) \\
Lack of available assessment tools, procedures and strategies (5) \\
Interpersonally sensitive (4) \\
He tried to tell us - indirectly (4) & Communications of distress (3) \\
Possible signs of abuse were attributed to ASD or depression (5) & $\begin{array}{l}\text { Unusual sexual topics (2) } \\
\text { Reluctance to return home (3) }\end{array}$ \\
& Irritable (5) \\
Angry outbursts (5) & Guarded and anxious (4) \\
Guilt and shame (3) & Few expressions of joy (3)
\end{tabular}

Table 2. Overview of themes and subthemes, with prevalence among informants indicated in parentheses. 
Appendix. Interview schedule.

How would you describe the patient's admission and stay in the ward?

What was your role?

How was the assessment conducted?

How would you describe the patient?

What challenges did you notice?

What symptoms did he have? How did you notice them?

What are your thoughts about the assessment now?

Was there anything during the admission that gave you pause or made you react?

What were your thoughts when you learned that the patient had been the victim of sexual abuse?

Did you have any thoughts about abuse during the admission?

When you look back, knowing what you do now, is there anything from the admission that you see in a different light?

Is there anything we could have done to uncover it, the way you see it?

Any more investigation, assessment tools, or something we should have asked?

Is there anything else you have thought about that you would like to say in this interview? 